\title{
Nature-Deficit Disorder
}

«Die Wälder waren mein Ritalin», bekannte der amerikanische Journalist und Umweltaktivist Richard Louv in seinem Bestseller «Last Child in the Woods» [1] von 2005. Er prägte den Ausdruck «Naturdefizit» für ein Syndrom von Aufmerksamkeitsstörungen, Überaktivität, Gewaltbereitschaft, Übergewicht und weitere psychische Störungen wie Depressionen im Kinderund Jugendalter. Zahlreiche Studien und Forschungsansätze belegen seine Beobachtungen über die Auswirkungen von Naturerlebnissen auf das geistige, spirituelle und körperliche Wohlbefinden. Waldkindergärten, Wildniscamps für Schwererziehbare, Trekkings für Drogensüchtige, Baumhausbewegungen und Naturschulen berufen sich auf seine Rezepte gegen eine denaturierte Lebensweise. Spielzeiten mit unstrukturiertem Material sollen Phantasie und Forschungsdrang fördern, denn Kletterbäume bauen Stress ab und der Anblick von Aquarien senkt den Blutdruck. Der Verlust an originären primären Erfahrungen wie taktile Sinneswahrnehmungen führt zu einem kulturellen Autismus. Louv plädiert für eine neue Umwelterziehung: «Was nützt das Wissen um den Regenwald, wenn man den Wald vor der Haustür nicht kennt?» Viele Ideen $\mathrm{zu}$ wohnungsnahen Verbesserungen sind seither in den westlichen Industriestaaten umgesetzt worden. Dazu gehören Bachrenaturierungen, grüne Dächer, urbane Bienenzucht und innerstädtische Grünflächen, die Kindern und Familien zur Verfügung stehen.

Bereits heute lebt mehr als die Hälfte der Weltbevölkerung in rasant wachsenden Millionenstädten. Immer mehr Menschen wohnen in Hochhäusern, arbeiten auch tags bei Kunstlicht und erholen sich in virtuellen Spielwelten. Der Zoologe Konrad Lorenz prägte für diese Verarmung das böse Wort von der «Verhausschweinung des Menschen.»Die extreme Domestizierung in den Betonwüsten einer Grossstadt bekommt den Menschen nicht. «Es ist nicht auszudenken, wie gefährlich die Welt ohne Tiere sein wird», meinte dazu Elias Canetti. Armut und Deprivation

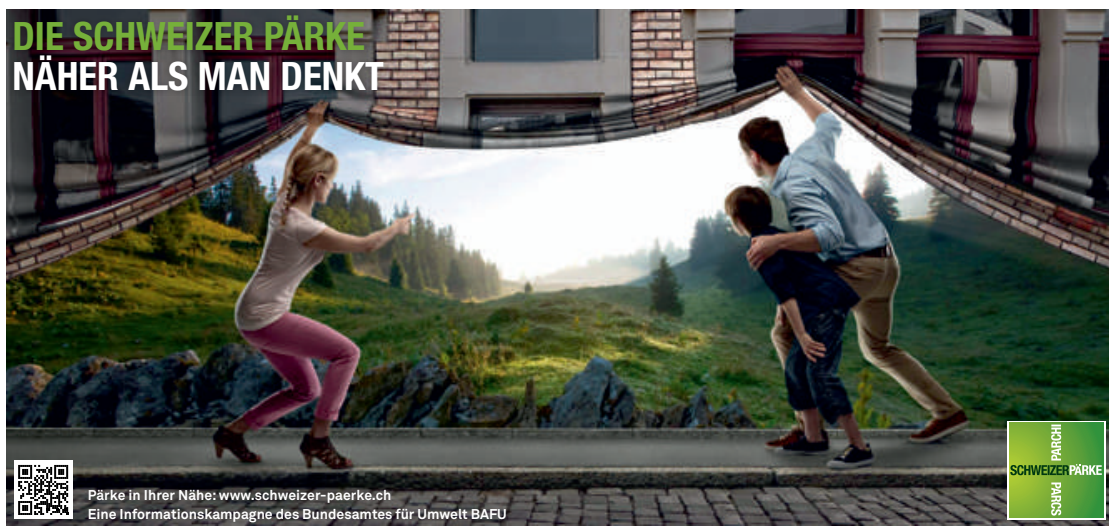

sind der Nährboden für Gewalt und Wahnsinn. Die zunehmende Mobilität und Zersiedelung hat hierzulande den gleichen Effekt. «Ein vaterländisches Heiligtum für die Schöpfung, ein Rütli der Natur» beschloss das Schweizer Parlament 1914 im Unterengadin zu verwirklichen. Die Bundeskampagne «Die Schweizer Pärke. Näher als man denkt» (www.schweizer-paerke. ch) wirbt mit Plakaten für Naturreservate. Eine hochhackige Mama in Leggings hebt den Vorhang mit der aufgemalten grauen Stadtkulisse. Eine Inszenierung zur sanften Tourismusförderung in ländlichen Regionen, nach ökologischen Kriterien bewertet und finanziert. Vierzehn regionale Naturparks von nationaler Bedeutung sind eine gute Sache, sofern sie keine Alibifunktion haben. Denn ebenso wichtig wären kindergerechte Quartiere, begehbare öffentliche Räume, sichere Schulwege, neue Wohnkonzepte, ein haushälterischer Umgang mit Landressourcen, eine wirksame Eindämmung der Autoflut und soziale Gerechtigkeit.

Begriffe wie Natur, Umwelt oder Mitwelt soll man in diesem Zusammenhang nüchtern gebrauchen. Gemeint ist hier etwas, das ohne menschliche Einwirkung entstanden ist, etwas, das zweckfrei in unmittelbarer Nähe existiert, etwas, das ohne Flugstunden, ohne Transa-Arsenal und Outdoor-Equipment unmittelbar erfahrbar bleibt. Wir brauchen ein Gegenüber, das grösser ist als wir, einen nicht-menschlichen Massstab, der unsere Vergänglichkeit und absolute Entbehrlichkeit auf diesem Planeten erfahren lässt. Man könnte es Transzendenz nennen oder einfach nur ein Gefühl von Zugehörigkeit und Staunen. Louv ist nicht der erste, der diese Einsichten formuliert. Es liegt an uns Erwachsenen, welche Welt wir den Kindern überlassen wollen. Die Einstellung zur Umwelt ist auch ein medizinisches Anliegen, hochpolitisch und subversiv, weil sie unsere Lebensweise radikal in Frage stellt.

Das neuste Themenheft von Greenpeace [2] ist der neuen Wildnis, gewachsen aus industriellen Ruinen, gewidmet. Der postapokalyptischen Landschaft von Tschernobyl, der Unterwasserwelt des Bikini-Atolls, dem grünen Band des ehemaligen Eisernen Vorhangs, dem Brachland der Schwerindustrie, den überwachsenen Fabrikhallen von Detroit. Unfreiwillige Parks in Katastrophenzonen, Denkmäler menschlicher Dummheit und Raffgier. Denn auch das wäre eine Möglichkeit: einfach weiterwursteln wie bisher. Für eine $\mathrm{Zu}$ kunft ohne uns.

Erhard Taverna

1 Louv R. Das letzte Kind im Wald. Freiburg i. Br.: Herder; 2013.

2 Greenpeace. Zwischen Furcht und Ehrfurcht: Die Wildnis. Magazin 3/2014. 